\title{
Sub-Conjunctival Haemorrhage Following Maxillary Third Molar Extraction - A Rarity
}

\author{
Karthik Ragupathy ${ }^{1}$, Geetha Rajendran², Sanjay Pasupathy ${ }^{3}$, Ganesh Ramakrishnan ${ }^{4}$, Kiruthika Shriranjani ${ }^{5}$ \\ 1, 2, 3, 4, 5 Department of Dentistry, Sri Manakula Vinayagar Medical College \& Hospital, Pondicherry. India.
}

\section{INTRODUCTION}

Third molar extraction remains one of the most common surgical procedures performed in dentistry either by intra-alveolar or trans alveolar methods; yet such a common surgical procedure sometimes results in relatively rare complications. The incidence of complications can be reduced by proper preoperative planning, knowledge of the surgical anatomy, good surgical technique and recognition of complications. Sub conjunctival haemorrhage after maxillary third molar extraction is one such complication, which till now not more than three cases of similar findings have been reported in the literature. The purpose of this article is to present a rare case of sub conjunctival haemorrhage after maxillary right third molar extraction in a 56-year-old female reported at The Department of Oral and Maxillofacial Surgery, Sri Manakula Vinayagar Medical College and Hospital, Pondicherry, India.

\section{PRESENTATION OF CASE}

A 56-year- old female reported to the Oral and Maxillofacial Surgery outpatient clinic at the Sri Manakula Vinayagar Medical College and Hospital a day after having her right maxillary third molar extracted by a general dentist with the complaints of mild swelling in right mid face region and redness in her right eye (Figure. 1a \& 1b). Detailed history revealed that the patient noticed redness in her right eye on the day of the extraction of her right maxillary third molar.

Extraction was performed under local anaesthesia with adrenaline ( $2 \%$ lidocaine and 1: 200000 adrenaline). Her vital signs recorded were unremarkable and within normal limits. Patient medical history was unremarkable and did not have any history of systemic diseases such as diabetes, hypertension, and bleeding disorders.

Extraoral examination revealed mild swelling in right midface region and diffuse Sub conjunctival haemorrhage in her right eye without any disturbances in vision and eyeball movements.

Intraoral examination revealed normal-appearing mucosa and healing extraction socket in the right maxillary third molar region. Computed tomogram scan was taken which showed enlarged right superior ophthalmic vein without any signs of maxillary tuberosity fracture and optic nerve compression (Figure. 2).

Ophthalmologist opinion was obtained; a conservative approach with antibiotic eye drops and lubricants were prescribed. Close monitoring of the patient's vision was regularly carried out; there was a significant reduction in sub conjunctival haemorrhage over the next 5 days.

\author{
Corresponding Author: \\ Dr. Karthik Ragupathy, \\ No. 25, Assistant Professor Quarters, \\ Sri Manakula Vinayagar Medical College \\ \& Hospital Campus, Kalitheerthalkuppam, \\ Pondicherry - 605107, India. \\ E-mail: drsrkarthik@gmail.com
}

DOI: $10.14260 /$ jemds/2021/401

How to Cite This Article:

Ragupathy K, Rajendran G, Pasupathy S, et al. Sub conjunctival haemorrhage following maxillary third molar extraction a rarity. J Evolution Med Dent Sci 2021;10(26):1954-1956, DOI: 10.14260/jemds/2021/401

Submission 24-02-2021,

Peer Review 01-05-2021,

Acceptance 07-05-2021,

Published 28-06-2021.

Copyright (C) 2021 Karthik Ragupathy et al. This is an open access article distributed under Creative Commons Attribution License [Attribution 4.0 International (CC BY 4.0)] 

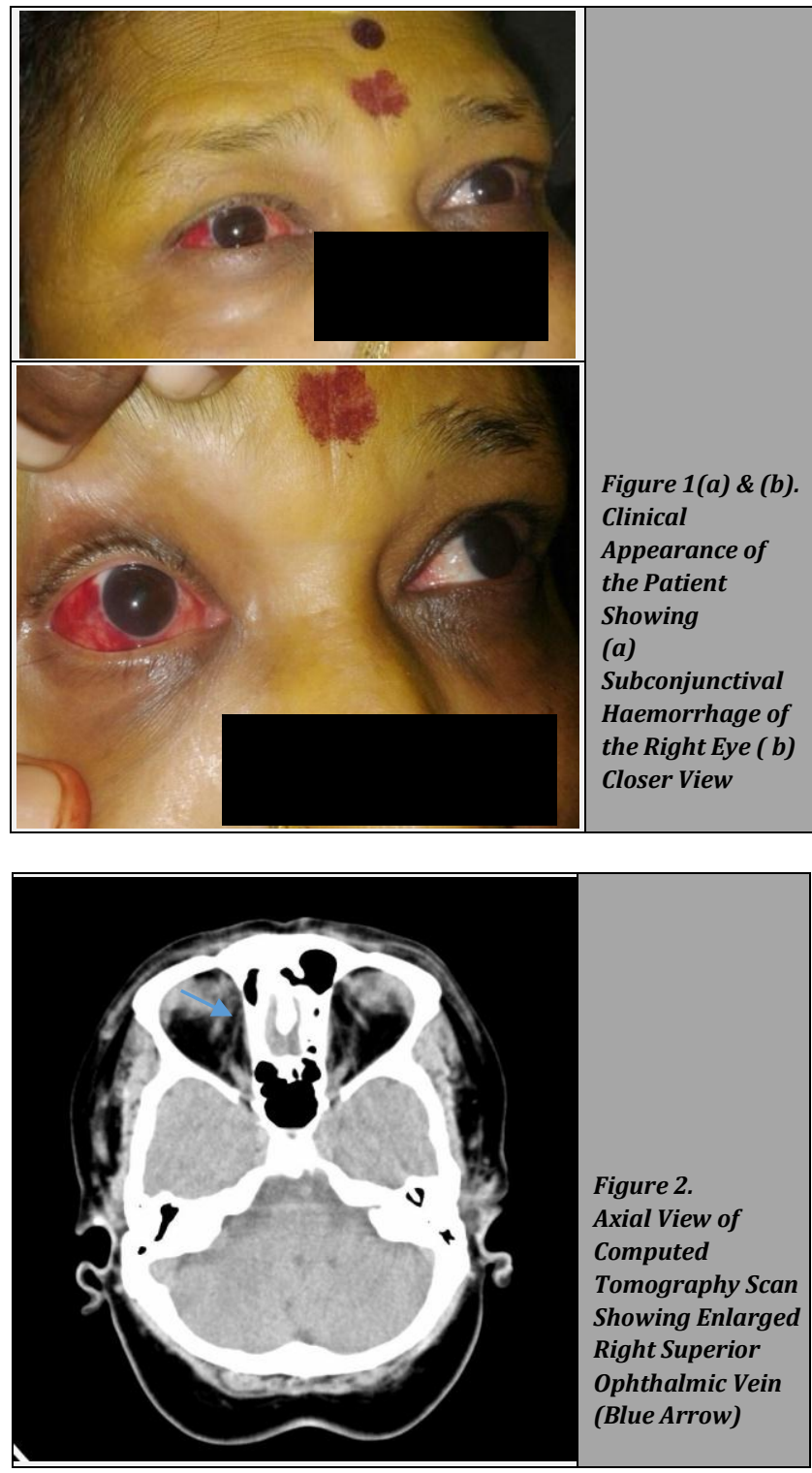

\section{DISCUSSION}

Third molar extraction is the most common minor surgical procedure performed by oral and maxillofacial surgeons, and most third molar extractions are performed without intraoperative or postoperative complications. The incidence of complications related to third molar extraction ranges from $4.6 \%$ to $30.9 \% .^{1}$ The most commonly reported complications during third molar extraction are alveolar osteitis, infection, bleeding, and paresthesia.1,6-9 Other complications, such as fracture of jawbones, fracture of the maxillary tuberosity, oroantral communication, displacement of the tooth, and temporomandibular joint dislocation were rarely encountered during third molar extraction. ${ }^{10-12}$ Persistent post extraction haemorrhage may result from inadequate or poor haemostasis. Incidence of clinically significant post extraction haemorrhage ranges from $0.2 \%$ to $5.8 \%{ }^{1}$ Post extraction haemorrhage is classified commonly into Primary haemorrhage, Reactionary haemorrhage and secondary haemorrhage. Primary haemorrhage - bleeding at the time of the surgery. Reactionary haemorrhage - bleeding two to three hours after the surgery and Secondary haemorrhage - can occur up to 14 days after the surgical procedure. Sub conjunctival haemorrhage is a common benign disorder of the eye with a characteristic acute ocular redness underneath the conjunctiva. ${ }^{2}$ The causes of it can be classified into ocular causes and systemic causes.

Ocular causes of sub conjunctival haemorrhage include local trauma to the globe, orbital injuries, and acute inflammation of the conjunctiva, conjunctivochalasis, conjunctival tumours, ocular adnexal tumours, contact lens usage, and ocular surgery.13-15 Systemic causes include systemic vascular diseases such as systemic hypertension, arteriosclerosis, hyperlipidaemia and diabetes mellitus, haematological disorders, severe venous congestion, carotid cavernous fistulas, drugs, menstruation. ${ }^{16-19}$

Sub conjunctival haemorrhage following extraction of maxillary third molar reported in our case is a very rare finding. To our knowledge, not more than three cases of sub conjunctival haemorrhage following tooth extraction have been reported in the scientific literature..$^{3-5}$

The mechanism of the sub conjunctival haemorrhage after tooth extraction in our case is debatable. The possible explanation would be a traumatic injury to the pterygoid plexus or its tributaries while giving local anaesthetic injection or during extraction.

The other possible path of spread is that bleeding from posterior superior alveolar artery or its branches during or after extraction spreading superiorly through the pterygomaxillary and infratemporal spaces into the intraorbital compartment. The CT scan revealed enlarged right superior ophthalmic vein without any evidence of maxillary tuberosity fracture indicating possibility of injury to pterygoid plexus or its tributaries in our case. Brahmin and Warburton ${ }^{3}$ in their study reported a case of intraorbital hematoma following the extraction of an upper third molar.

According to their study, the possibility of post-extraction haemorrhage might have occurred from one of the tributaries of the pterygoid plexus of veins such as the posterior superior alveolar vessels, deep facial veins, or even from the pterygoid plexus itself. Uncontrolled bleeding from the extraction site may track up along the fascial spaces such as pterygomaxillary space, infratemporal space and eventually communicates with intraorbital compartment through the inferior orbital fissure resulting in sub conjunctival haemorrhage. This explanation provides a possibility of post-extraction haemorrhage that might have spread from pterygomaxillary space into the orbit. In our case, we postulate that active bleeding from pterygoid plexus, or its tributaries could have spread in to the intraorbital compartment resulting in sub conjunctival haemorrhage.

\section{CONCLUSIONS}

We report a rare case of sub conjunctival haemorrhage followed by an uneventful extraction of maxillary third molar. We postulate that active bleeding from pterygoid plexus or its tributaries might have extended into the orbit resulting in sub conjunctival haemorrhage. The risk of sub conjunctival haemorrhage associated with maxillary third molar extraction is extremely rare, and hence it is important to be aware of potential complications, immediate recognition, and early intervention to prevent functional impairment to the patient. 
Financial or other competing interests: None.

Disclosure forms provided by the authors are available with the full text of this article at jemds.com.

\section{REFERENCES}

[1] Bouloux GF, Steed MB, Perciaccante VJ. Complications of third molar surgery. Oral Maxillofacial Surg Clin N Am 2007;19(1):117-28.

[2] Tarlan B, Kiratli H. Subconjunctival hemorrhage: risk factors and potential indicators. Clin Ophthalmol 2013;7:1163-70.

[3] Warburton G, Brahim JS. Intraorbital hematoma after removal of upper third molar: a case report. J Oral Maxillofac Surg 2006;64(4):700-4.

[4] Kumar RA, Moturi K. Subconjunctival ecchymosis after extraction of maxillary molar teeth: a case report. Dent Traumatol 2010;26(3):298-300.

[5] Thirumurugan K, Munzanoor RR, Prasad GA, et al. Maxillary tuberosity fracture and subconjunctival hemorrhage following extraction of maxillary third molar. J Nat Sci Biol Med 2013;4(1):242-5.

[6] Bui CH, Seldin EB, Dodson TB. Types, frequencies and risk factors for complications after third molar extraction. J Oral Maxillofac Surg 2003;61(12):1379-89.

[7] Moghadam HG, Caminiti MF. Life-threatening hemorrhage after extraction of third molars: case report and management protocol. J Can Dent Assoc 2002;68(11):670-4.

[8] Heiland M, Weber M, Schmelzle R. Life-threatening bleeding after dental extraction in a hemophilia a patient with inhibitors to factor VIII: a case report received from University Hospital Hamburg-Eppendorf, Hamburg, Germany. J Oral Maxillofac Surg 2003;61(11):1350-3.

[9] Bertram AR, Rao ACA, Akbiyik KM, et al. Maxillary tuberosity fracture: a life-threatening haemorrhage following simple exodontia. Aust Dent J 2011;56(2):2125.

[10] Baba J, Iwai T, Endo H, et al. Maxillary tuberosity fracture and ophthalmologic complications following removal of maxillary third molar. Oral Surg 2017;10(1):43-7.

[11] Sayed N, Bakathir A, Pasha M, et al. Complications of third molar extraction: a retrospective study from a tertiary healthcare centre in Oman. Sultan Qaboos Univ Med J 2019;19(3):e230-5.

[12] Pourmand PP, Sigron GR, Mache B, et al. The most common complications after wisdom-tooth removal: part 2: a retrospective study of 1,562 cases in the maxilla. Swiss Dent J 2014;124(10):1047-61.

[13] De Carvalho RWF, De Araújo Filho RCA, Do Egito Vasconcelos BC. Assessment of factors associated with surgical difficulty during removal of impacted maxillary third molars. J Oral Maxillofac Surg 2013;71(5):839-45.

[14] Rajati M, Bakhshaee M, Khazaeni K. Periorbital ecchymosis and subconjunctival hemorrhage following ear surgery. ISRN Otolaryngol 2013;2013:791068.

[15] Mimura T, Yamagami S, Usui T, et al. Location and extent of subconjunctival hemorrhage. Ophthalmologica 2010;224(2):90-5.

[16] Kaimbo DKW. Epidemiology of traumatic and spontaneous subconjunctival haemorrhages in Congo. Bull Soc Belge Ophtalmol 2009;311:31-6.

[17] Cagini C, Iannone A, Bartolini A, et al. Reasons for visits to an emergency center and hemostatic alterations in patients with recurrent spontaneous subconjunctival hemorrhage. Eur J Ophthalmol 2016;26(2):188-92.

[18] Fierro T, Bartolini A, Mezzasoma AM, et al. Prevalence of hemostatic alterations in patients with recurrent spontaneous subconjunctival hemorrhage. Clin Chem Lab Med 2016;54(1):97-103.

[19] Mimura T, Usui T, Yamagami S, et al. Recent causes of subconjunctival hemorrhage. Ophthalmologica 2010;224(3):133-7. 